\title{
A RARE CASE OF LARGE SOLITARY CEREBRAL HYDATID CYST
}

Sachin Khanduri ${ }^{1}$, Sumit Agrawal'2, Anshul Raja ${ }^{3}$, Amit Mishra ${ }^{4}$, Mriganki Chaudhary ${ }^{5}$

\section{HOW TO CITE THIS ARTICLE:}

Sachin Khanduri, Sumit Agrawal, Anshul Raja, Amit Mishra, Mriganki Chaudhary. "A Rare Case of Large Solitary Cerebral Hydatid Cyst". Journal of Evolution of Medical and Dental Sciences 2015; Vol. 4, Issue 54, July 06;

Page: 9511-9514, DOI: $10.14260 /$ jemds/2015/1376

ABSTRACT: Cerebral hydatid cyst is a rare entity seen in upto 2\%.[1] It can be primary (single) or secondary (multiple). 18 year old male presented with chief complaints of headache, nausea, vomiting. Non Contrast Computed Tomography (NCCT) and Contrast Enhanced Magnetic Resonance Imaging (CEMRI) findings revealed possibility of hydatid cyst. Surgery remains mainstay of treatment. The patient was operated and pathology report confirmed the diagnosis.

KEYWORDS: Cerebral, hydatid, Non Contrast Computed Tomography, Contrast Enhanced Magnetic Resonance Imaging, surgery.

INTRODUCTION: Larval stage of parasitic tapeworm Echinococcus granulosus is called hydatid cyst. Liver is most commonly involved organ (77\%), followed by lungs (43\%). However, brain involvement is $2 \%$, heart $2 \%$, kidneys $2 \%$, orbit $1 \%$, spinal cord $1 \%$, spleen, spine, spermatic cord and soft tissues. ${ }^{[1]}$ It is usually seen in children and adolescents. It's incidence is reported to be $0.2 \%$ of all intracranial space occupying lesions (SOL).[2] Definite host of tapeworm Echinococcus granulosusis dog, mammals being intermittent hosts. Human infection is usually via faeco oral transmission.

CASE REPORT: We present a case of 18 year old male who presented to emergency department with signs and symptoms of increased intracranial tension in the form of headache, nausea, vomiting which had an insidious onset and was progressive in nature. Patient was then referred to department of radiodiagnosis for Non contrast computed tomography (NCCT) which showed a large well defined cystic SOL of cerebrospinal fluid (CSF) density measuring approximately $6.9 * 5.8 \mathrm{~cm}$ noted in right parietal lobe in the Middle cerebral artery (MCA) territory causing mass effect in the form of midline shift to left and compression of lateral ventricles. No perifocal edema was noted.

To confirm the diagnosis patient was taken up for contrast enhanced magnetic resonance imaging (CEMRI) which revealed a non-enhancing cystic SOL displaying CSF signals on all pulse sequences and mass effect. The cyst was removed surgically and pathology report confirmed the diagnosis.

CONCLUSIONS: Intracranial hydatid disease is among the rare entities with reported incidence of 1$2 \%{ }^{[3][4][5]}$ Cerebral hydatid cysts can be primary (single) or secondary (multiple). They commonly involve the MCA territory like in our case. Other rarer sites are posterior fossa, intraventricular and intraorbital. Clinical features are focal neurological deficit and increased intracranial tension due to large size. Cyst is composed of endocyst, ectocyst and pericyst. In brain, pericyst is very thin because of minimal host reaction.

Differential diagnosis includes cerebral abscess, arachnoid cyst and brain tumours. Absence of any perifocal edema, absence of post contrast enhancement, typical CSF intensity on all CEMRI 
pulse sequences and CSF attenuation on NCCT rule out the possibility of cerebral abscess and brain tumors. Intra axial location of the SOL ruled out possibility of arachnoid cyst.

Blood tests revealed normal findings contrary to eosinophilia which is usually found in Echinococcal infestations. This was possibly due to the fact that brain tissue does not evoke enough host response leading to false negative results.

Treatment of choice is surgery, however spillage is a serious concern per operatively. Dowling-Orlando technique involves lowering the head of operating table and instilling warm saline between cyst and surrounding brain. This reduces the chance of rupture enormously.[6] Post operatively antibiotic cover usually albendazole is given.

Teaching Point: Possibility of cerebral hydatid though rare should be considered specially in children and adolescents where epidemiology and imaging favours the diagnosis. Also apart from a CT, MRI should also be undertaken to look for any intracystic content and features of any rupture. Pre-operative diagnostic workup is necessary because rupturing a hydatid cyst preoperatively, it will lead to catastrophic results.

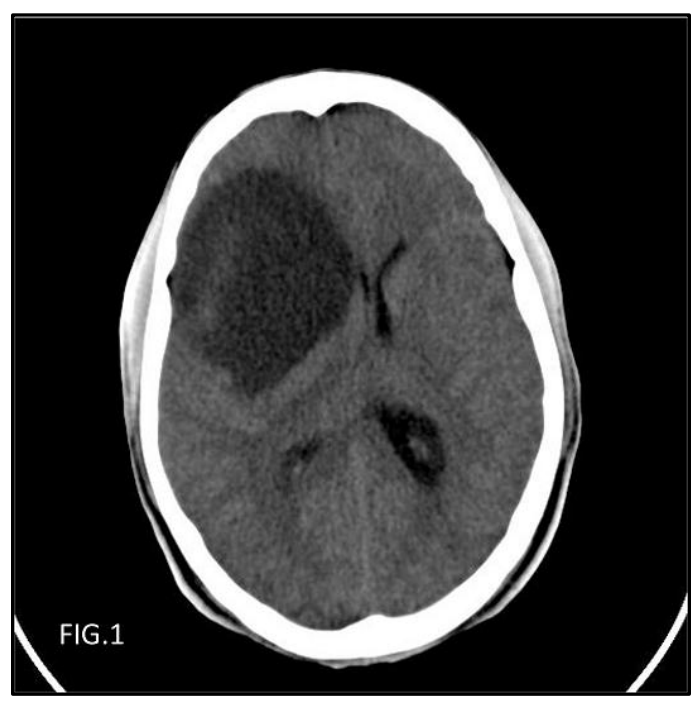

\section{Figure 1}

Fig. 1: NCCT axial scan showing a well defined cystic SOL of CSF attenuation noted in right middle cerebral artery territory measuring approximately $6.9 * 5.8 \mathrm{~cm}$ causing mass effect in the form of midline shift to left and compression of right lateral ventricles. 


\section{CASE REPORT}

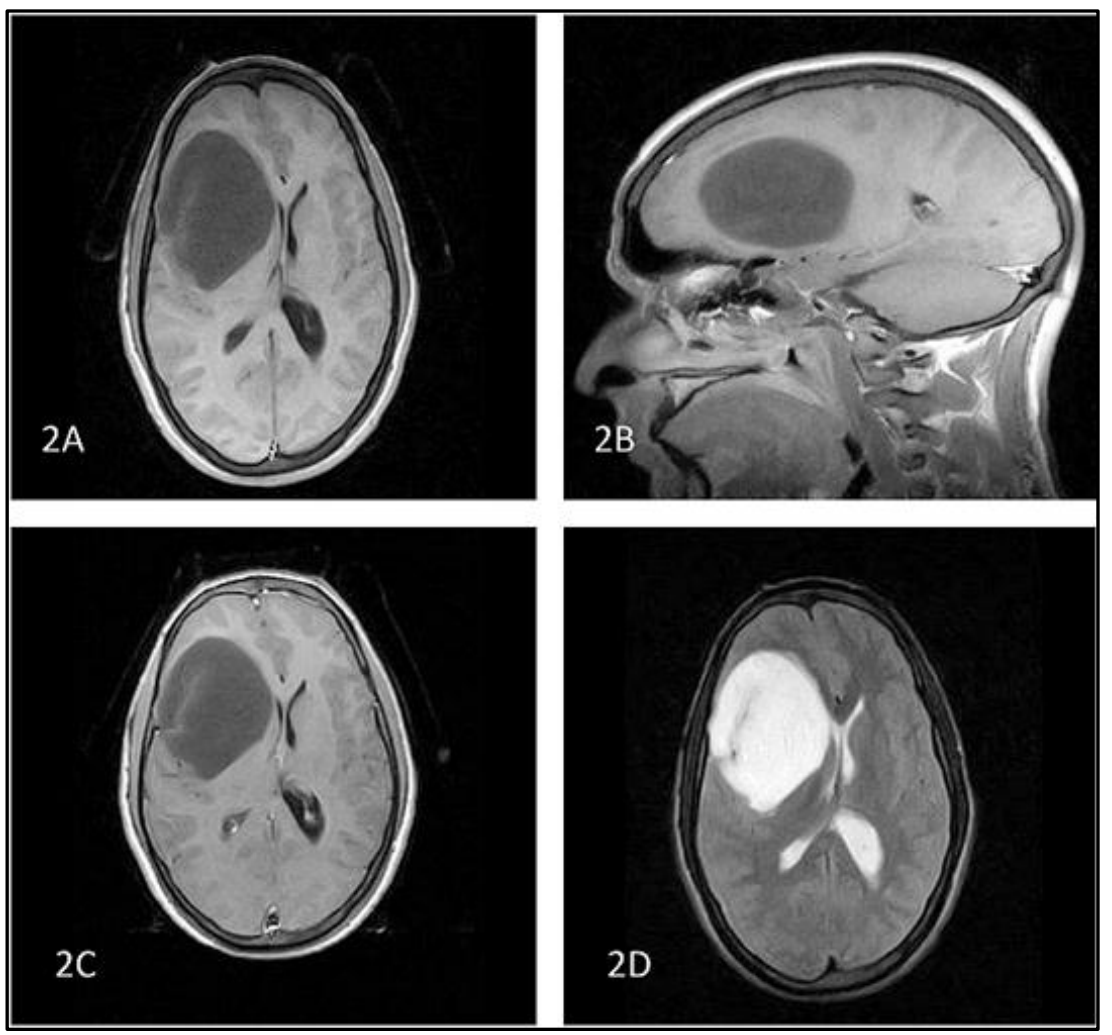

Figure 2

Fig. 2: $[\mathrm{A}] \mathrm{MRI} \mathrm{T}_{1} \mathrm{~W}$ axial [B] MRI $\mathrm{T}_{1} \mathrm{~W}$ sagittal [C] CEMRI $\mathrm{T}_{1} \mathrm{~W}$ axial [D] MRI $\mathrm{T}_{2} \mathrm{~W}$ axial scan showing an intra axial well defined cystic SOL displaying CSF signal intensity with no post contrast enhancement and no perifocal edema noted in right middle cerebral artery territory measuring approximately $6.9 * 3.8$ cmcausing mass effect in the form of midline shift to left and compression of right lateral ventricles.

\section{REFERENCES:}

1. Nemati A, Kamgarpour A, Rashid M, Nazari S. Giant Cerebral Hydatid Cyst in a child- A Case Report and Review of Literature. BJMP 2010; 3(3): a338.

2. Dharker SR: Hydatid disease. In: Text Book of Neurosurgery, Second edition. Eds. Ramamurthi B, Tandon PN. Churchill Livingstone, New Delhi 1996; 535-544.

3. Ersahin Y, Mutluer S, Güzelbag E. Intracranial hydatid cysts in children. Neurosurgery 1993; 33(2): 219-224.

4. Cavusoglu H, Tuncer C, Ozdilmaç A, Aydin Y. Multiple Intracranial Hydatid cysts in a boy. Turk Neurosurg 2009; 19(2): 203-207.

5. Gana R, Skhissi M, Maaqili R, Bellakhdar F. Multiple infected cerebral hydatid cysts. J ClinNeurosci 2008; 15(5): 591-593.

6. Carrea R, Dowling E Jr, Guevara JA. Surgical treatment of hydatid cysts of the central nervous system in the pediatric age (Dowling's technique). Childs Brain 1975; 1(1): 4-21. 


\section{AUTHORS:}

1. Sachin Khanduri

2. Sumit Agrawal

3. Anshul Raja

4. Amit Mishra

5. Mriganki Chaudhary

\section{PARTICULARS OF CONTRIBUTORS:}

1. Professor, Department of RadioDiagnosis, Era Lucknow Medical College and Hospital.

2. Junior Resident, Department of RadioDiagnosis, Era Lucknow Medical College and Hospital.

3. Junior Resident, Department of RadioDiagnosis, Era Lucknow Medical College and Hospital.

FINANCIAL OR OTHER COMPETING INTERESTS: None
4. Junior Resident, Department of RadioDiagnosis, Era Lucknow Medical College and Hospital.

5. Junior Resident, Department of RadioDiagnosis, Era Lucknow Medical College and Hospital.

\section{NAME ADDRESS EMAIL ID OF THE CORRESPONDING AUTHOR:}

Sumit Agrawal,

P. G. Boy's Hostel,

Era Lucknow Medical College and Hospital, Sarfarazganj, Hardoi Road,

Lucknow - 226003, U. P.

E-mail: dr_sumit_agrawal@yahoo.com

Date of Submission: 03/06/2015.

Date of Peer Review: 04/06/2015.

Date of Acceptance: 29/06/2015.

Date of Publishing: 06/07/2015. 